\title{
Epistemología axiológica y conocimiento transdisciplinar: estrategias cognoscitivas para el reconocimiento y cultivo de la cualidad humana profunda y la dimensión sagrada de la existencia ${ }^{1}$
}

\author{
Axiological epistemology and transdisciplinary knowledge: \\ cognitive strategies for recognition and cultivation of the human deep quality and the \\ sacred dimension of existence
}

Sergio Néstor Osorio García*

\begin{abstract}
Resumen
El diagnóstico de las sociedades europeas actuales que se hacen viables a través de la producción de conocimiento científico-técnico es simple en su formulación: se trata de sociedades que viven de la creación constante de conocimiento y, dadas las condiciones socio-laborales y económicas implementadas desde el modelo de sociedad neoliberal, es el conocimiento abstracto el que está asociado al interés de lucro de unos cuantos en detrimento de todos, el que está liderando y jalonando la lógica cultural de las sociedades de conocimiento, sin ningún miramiento axiológico. Es decir, sin postular y discernir los fines y valores comunes que pueden motivar a los humanos para vivir a mediano y largo plazo a la manera humana. Así las cosas, las actuales sociedades europeas, -aunque no sólo ellas-, son sociedades de conocimiento, (porque viven de la creación continua de conocimientos científico-técnicos o tecno-científicos). Pero, al mismo tiempo, son sociedades que se encuentran desmanteladas axiológicamente. Son sociedades que no tienen cómo direccionarse axiológicamente. Si la humanidad no recupera y cultiva esta dimensión constitutiva, no podrá hacerse viable o por lo menos no podrá hacerse viable a la manera humana. La reflexión presenta la propuesta de una epistemología axiológica (M. Corbí) y la propuesta de un conocimiento transdisciplinar (B. Nicolescu) como "dispositivos" que de cultivarse de manera explícita, podrán evitar el colapsamiento humano en las sociedades de conocimiento.
\end{abstract}

Palabras claves: Epistemología axiológica; conocimiento y metodología transdisciplinar; cualidad humana profunda; dimensión sagrada de la existencia.

\begin{abstract}
The diagnosis of the current European societies, which are made possible through the production of scientific knowledge and technical, is simple in its formulation. They are societies in constant knowledge creation. Given socioeconomic and working conditions, implemented from the neo-liberal model of society, the abstract knowledge, associated with the profit of a few over the many, is leading the cultural logic of knowledge societies, without any axiological hesitation, That is to say, without postulating and discerning common goals and values that can motivate human beings to live for the human journey. Thus, the current European societies, but not only them, are knowledge societies, (because they live in the continuous creation of technical and scientific knowledge). At the same time, companies are axiologically dismantled. They are societies that do not have been axiologically oriented. If humanity does not recover and increase this constitutive dimension, may not be feasible in human form. Our reflection presents a proposal for an axiological epistemology (M. Corbi) and the proposal of a transdisciplinary knowledge (B. Nicolescu) as "devices" that explicitly cultivated, can prevent human collapse in knowledge societies.
\end{abstract}

Keywords: Axiological epistemology; knowledge and transdisciplinary methodology; deep human quality; sacred dimension of existence.

Artículo recibido el 19 de octubreo 2014 y aprobado el 20 marzo 2015

${ }^{1}$ El presente artículo hace parte del proyecto de investigación HUM 1517: La Bioética como ética de la responsabilidad planetaria, que se realiza con financiación de la Vicerrectoría de Investigaciones de la Universidad Militar Nueva Granada, Bogotá-Colombia.

* Doctorando en Teología. Profesor en la Facultad de Educación y Humanidades - Universidad Militar Nueva Granada (Bogotá). País de origen: Colombia. E-mail: sergio.osorio@unimilitar.edu.co sergionestorosorio@gmail.com. 
Sólo cuando uno aprende a quedarse en la total intemperie, sin techo que lo proteja del cosmos inmenso, sin paredes que le resguarden de los vientos, sin refugio alguno; solo cuando uno renuncia a poder disponer de un cercado donde sentirse menos insignificante en el vasto espacio; solo, cuando con los años, uno aprende a no esperar que la verdad tenga un rostro delimitado y próximo; solo cuando se ha aprendido, por fin, a no intentar, de mil maneras, salvarse; sólo entonces, la verdad es inhóspita, pero profundamente hospitalaria; despiadada como la inmensidad, pero acogedora como una amante; vacía como un abismo, pero haciéndose sentir con una presencia plena y cálida.

CORBÍ, 2009, p. 11.

Hay una gran pobreza espiritual presente en nuestra Tierra. Se manifiesta como el miedo, la violencia, el odio y el dogmatismo. En un mundo con más de 8.000 disciplinas académicas, más de 10.000 religiones y movimientos religiosos y más de 6.000 lenguas, ¿Cómo podemos soñar una comprensión mutua y la búsqueda la paz? Hay una evidente necesidad de una nueva espiritualidad, conciliando la tecno-ciencia y la sabiduría.

NICOLESCU, 2008a, p. 509.

\section{Pretensión de la reflexión}

La característica específica de los seres humanos desde el punto de vista antropo-lingüístico es que tienen un doble acceso a la realidad: uno primero, funcional y lingüísticamente mediado por sus intereses de supervivencia, y otro, último, absoluto, silencioso que accede a la realidad como si los intereses de sobrevivencia no estuvieran presentes. El primero de ellos, da origen a la cualidad humana y el segundo a la cualidad humana profunda (antigua espiritualidad). Este doble acceso a la realidad, -que se da de manera indivisible, pero al mismo tiempo diferenciable-, hace posible que el ser humano se haga viable, y se haga viable a la manera humana.

La epistemología axiológica que viene desarrollando el epistemólogo Marià Corbí y su equipo de trabajo en el Centro de Estudios de las Tradiciones de Sabiduría CETR, con sede en Barcelona (CETR, 2014), busca dotar a los humanos que conforman las sociedades de conocimiento, -aunque no sólo a ellos-, de un recurso para cultivar, de manera explícita, tanto de la cualidad humana como la cualidad humana profunda, valiéndose para ésta última de los testimonios escritos encontrados en las tradiciones religiosas y espirituales de la humanidad. Estos testimonios, asumidos desde una epistemología no-mítica, es decir leídos e interpretados como textos puramente simbólicos que comunican el acceso al conocimiento de la dimensión absoluta de la realidad y por tanto como actos 
comunicativos aptos para el reconocimiento y cultivo explícito de la cualidad humana profunda (antigua espiritualidad) ${ }^{2}$.

Por otro lado, con los aportes epistemológicos acaecidos para la humanidad desde el paradigma de la física cuántica y en especial con la reflexión sobre el conocimiento y la metodología transdisciplinar desarrollada por el físico de partículas Basarat Nicolescu y su grupo de trabajo en el Centro Internacional de Investigaciones y Estudios Transdisciplinares CIRET, con sede en París (CIRET, 2014), también se puede llegar a una comprensión del ser humano en la que su cualidad humana profunda (para emplear la terminología usada por Corbí) consistiría en el reconocimiento y cultivo de la dimensión absoluta de la realidad: para Nicolescu el acceso a la dimensión sagrada. Pero, comprendiendo esta dimensión sagrada de la existencia, como un punto de unión en, a través y más allá de las correlaciones isomórficas entre los conocimientos provenientes de la cultura tecno-científica y los conocimientos provenientes de la cultura humanística, religiosa y espiritual presentes en los diferentes contextos socio-culturales en los que los hombres tejen con otros su existencia.

Nicolescu entiende por cultura tecno-científica al matrimonio entre la ciencia fundamental y la tecnología desde los intereses desmedidos de la acumulación y del lucro: desde el imperativo tecnológico que nos dice que todo lo que se puede hacer, se hará, para bien o para mal. Desde la dinámica tecnocientífica, los saberes culturales y de manera específica el acceso socio-cultural y cognoscitivo a lo sagrado, se encuentran al borde de su eliminación. Y esto para

\footnotetext{
${ }^{2}$ Comprender la Cualidad humana profunda desde el ámbito de la antigua espiritualidad, es una estrategia de tipo comunicativo que ayuda a quienes han sido formados al interior de la tradición de experiencias cristianas, para señalar hacia aquella dimensión de la realidad en la que se hace "presente" lo indecible. Pero, si se interpreta desde otra tradición de experiencias humanas, el contrapunteo, entre Cualidad humana profunda y espiritualidad, no sólo no ayuda, sino que en el mejor de los casos aleja de lo que se quiere decir. El mismo Corbí es consciente de este problema y en no pocas ocasiones dice que es necesario dejar de lado el término espiritualidad, para hablar simple y llanamente de la Cualidad humana profunda, es decir de una saber que se cultiva y desarrolla sin ningún soporte externo a la condición humana. Pero, dado el contexto cultural en el que esta propuesta se mueve, (el contexto occidental) Corbí conserva pedagógicamente esta terminología. En cualquier caso hay que decir que no se trata de una nueva religión. La religión, como producto cultural de las cultura agrarias que modela la realidad y hace posible en el hombre el acceso a la dimensión absoluta de la realidad, en las sociedades de conocimiento que viven de la producción de conocimiento, como de la producción de bienes y servicios a partir de aquellos, es hoy epistemológica, sociológica, antropológica y culturalmente imposible. En este sentido, la cualidad humana profunda no sólo no continua la dimensión abierta por la antigua espiritualidad, sino que la transforma desde sus fundamentos. Cfr. CORBÍ, 2007.
} 
Nicolescu configura una tragedia que compromete y comprometerá cada vez más, la habitabilidad humana del planeta y la biosfera planetaria.

En este contexto, el conocimiento y la metodología transdisciplinar, -desde los postulados ontológicos y epistemológicos que le son propios a cada una de ellas, tiene la pretensión de brindarnos un “dispositivo” para que los humanos de la era actual puedan cultivar aquella dimensión que a la fecha se encuentra subdesarrollada, y que si no cultivamos de manera explícita en lo personal y en lo colectivo, la humanidad a largo plazo no podrá hacerse viable a la manera humana. 3

En lo que sigue haré el siguiente desarrollo: En un primer momento, y apoyándome en algunos autores provenientes de la sociología actual, pondré como telón de fondo la amenaza que se cierne sobre la humanidad actual; en segundo lugar, haré una presentación sinóptica de la propuesta corbiniana que ya he desarrollado en otras oportunidades (OSORIO, 2014), y una presentación más detallada de la propuesta de Basarat Nicolescu que es una poco más desconocida para los hispanoparlantes. Como colofón, finalizaré mi reflexión postulando la emergencia de una actitud transcultural, transreligiosa y transhumana como una consecuencia impostergable tanto de la epistemología axiológica como del conocimiento y la metodología transdisciplinar.

\section{El drama humano en la Era de la civilización tecno-científica}

La diagnóstico realizado tanto por Corbí como por Nicolescu (aunque con diferentes enfoques paradigmáticos), de las sociedades europeas actuales que se hacen viables a través de la producción de conocimiento científico, es simple en su formulación: se trata de sociedades que viven de la creación constante de conocimiento $\mathrm{y}$, dadas las condiciones socio-laborales y económicas implementadas desde el modelo de sociedad neoliberal, es el conocimiento

\footnotetext{
${ }^{3}$ El término técnico utilizado por Nicolescu no se asocia al significado de cultura entendida en la perspectiva sociológica o antropológica actual, sino más bien al significado de una mentalidad (saber): que fusiona determinados niveles de Realidad con determinados niveles subjetivos de percepción de la Realidad.
} 
científico-técnico (Corbí) o tecno-científico (Nicolescu), el que asociado al interés de lucro de unos cuantos en detrimento de todos, está liderando y jalonando la lógica cultural de las sociedades de conocimiento, sin ningún miramiento axiológico. Es decir, sin postular y discernir los fines y valores comunes que pueden motivar a los humanos para vivir a la manera humana.

Así las cosas, las actuales sociedades europeas,-aunque no sólo ellas-, son sociedades de conocimiento, (porque viven de la creación continua de conocimientos científico-técnicos tecno-científicos) como de los productos y servicios que se pueden generar desde aquellos como motor de la economía. Pero, al mismo tiempo, son sociedades que se encuentran desmanteladas axiologicamente (CORBÍ, 2012b; NICOLESCU, 1996). Son sociedades que no tienen cómo direccionarse axiológicamente.

Los dos acercamientos a la crisis axiológica, buscan brindar a la humanidad un “dispositivo" epistemológico que le posibilite el reconocimiento y cultivo explícito de la cualidad humana profunda. En ambos casos, si la humanidad no recupera y cultiva esta dimensión constitutiva, no podrá hacerse viable o por lo menos no podrá hacerse viable a la manera humana. Pues, de seguir con esa lógica actual claramente autodestructiva, terminará autodestruyéndose.

\subsection{Otros acercamientos a este mismo drama}

Las sociedades de la "segunda modernización”, vistas éstas desde la perspectiva del sociólogo alemán Ulrich Beck, son sociedades que a través de sus manos tecno-científicas tienen el potencial destructor para acabar con todo aquello que no esté en su lógica acumulativa, y con ello, están poniendo en grave peligro la sostenibilidad planetaria. Dicho de otra manera, las sociedades de la "segunda modernización”, son sociedades de riesgo (BECK, 2006 a, 2006b). Son sociedades que viven de producir conocimiento direccionado única y 
exclusivamente al lucro y al crecimiento económico de unos cuantos en detrimento de la totalidad (BECK, 2008)4.

Esta situación, aunque con un aparato metodológico muy distinto, también había sido elaborada en la década de los ochenta del siglo pasado por dos sociólogos que trabajan desde la perspectiva de la sociología fenomenológica inaugurada por Alfred Schütz. Me refiero al sociólogo vienés, residente en Estados Unidos, Peter Berger; y al sociólogo esloveno, también residente en Estados Unidos, Thomas Luckmann5. En el año 1973, Berger realizó un estudio muy sugerente sobre las transformaciones de la conciencia religiosa en la sociedad moderna y allí postuló la hipótesis según la cual la sociedad moderna es una

\footnotetext{
${ }^{4}$ Aunque Wikipedia no sea una fuente primaria de consulta y muchos de sus datos estén sujetos a corroboración, me parece muy sugerente la presentación que se hace de sociólogo Ulrich Beck, y esto por la proximidad con los planteamientos tanto de Corbí como de Nicolescu para realizar un diagnóstico de la sociedad actual. Por ello, transcribo lo que allí aparece: "Características de la 'Sociedad del Riesgo'. Definición: Fase de desarrollo de la sociedad moderna donde los riesgos sociales, políticos, económicos e industriales tienden cada vez más a escapar a las instituciones de control y protección de la sociedad industrial. Podemos distinguir ocho características destacadas: 1.Los riesgos causan daños sistemáticos a menudo irreversibles. 2. El reparto e incremento de los riesgos sigue un proceso de desigualdad social. 3. Riesgo, negocio con doble causa; riesgo y oportunidades de mercado. 4. Hay un vacío político e institucional. Los movimientos sociales son la nueva legitimación. 5. Las fuentes que daban significado colectivo a los ciudadanos están en proceso de "desencantamiento". 6. En las nuevas sociedades recae en el individuo un proceso de "individualización" a través de una desvinculación de las formas tradicionales de la sociedad industrial y una re-vinculación con otro tipo de modernización. 7. Las fuentes colectivas que dan significado a la sociedad se agotan y el individuo, busca de forma independiente, una identidad en la nueva sociedad. En situaciones de clase el ser determina la conciencia, mientras que en situaciones de riesgo es al revés, la conciencia determina el ser. 8. Retorno de la incertidumbre; riesgo como reconocimiento de lo impredecible y de las amenazas de la sociedad industrial. En la sociedad reflexiva, la sociedad se convierte en un problema para sí misma. La sociedad reflexiva se convierte en un concepto post-industrial el cual no habían pensado los clásicos como Max Weber. Su Pensamiento. Se puede ver cómo a lo largo de sus obras Beck se sitúa en una posición crítica, enfrentándose a las corrientes del postmodernismo. De esta manera, y junto con Giddens, Bauman y Mendez, defiende a la sociología reflexiva, para no abandonar el análisis crítico frente a los problemas actuales. Beck se acerca a los problemas de la nueva sociedad, que no son los mismos que describía la sociología de las sociedades precedentes, y encuentra una fuente de incertidumbre, inseguridad y riesgos. La sociedad postmoderna asume una carga de riesgo en su propia identidad que encierra una grave contradicción: el peligro de supervivencia de la especie. La "rentabilidad" del sistema corre el riesgo de la incertidumbre; no parte de la asunción de la seguridad y de un escenario sostenible en términos ecológicos, sino que conoce que existen márgenes de peligrosidad para la especie cuya cobertura no es, paradójicamente, prioritaria en un sistema guiado por la obtención de beneficios y una representación retórica de la racionalidad que oculta la racionalidad. Los medios de comunicación, tienen un papel muy importante en la representación de los riesgos y la búsqueda de soluciones, aumentando el poder y el control social. El pensamiento de Beck está marcado por las constantes de una sociedad sometida a fuertes riesgos y a procesos de individualización. Para él la actualidad se forma con las noticias de las catástrofes ecológicas, las crisis financieras, el terrorismo, las guerras preventivas. Beck distingue una primera modernización, que discurre a lo largo de la industrialización y la creación de la sociedad de masas, de una 'segunda modernización', propia de una sociedad que tiende a la globalización y está en constante desarrollo tecnológico. En la era industrial la estructura cultural y social era la familia, pero luego ese núcleo se rompe dando lugar a la individualización, aumentándose la incertidumbre del individuo en la sociedad de riesgo. Parece ser que esto es producto del neoliberalismo económico, y no solo afecta al plano personal sino que también afecta a las instituciones.". WIKIPEDIA, 2014.

${ }^{5}$ Peter Ludwing Berger es un teólogo luterano y sociólogo que se hizo muy famoso con el libro, escrito a dos manos con Luckmannn sobre la construcción social de la realidad (BERGER; LUCKMANN, 1967); en castellano: BERGER; LUCKMANN, 1986. Desde 1981 Berger es profesor de sociología y teología en la Universidad de Boston. Desde 1985 ha sido Director del Instituto para el Estudio de la Cultura Económica, que con el tiempo y ayuda de Berger cambió de nombre. Hoy se conoce como el Instituto de Cultura, Religión y Asuntos Mundiales.
} 
sociedad anómica ${ }^{6}$ (Corbí y Nicolescu dirían que es una sociedad desmantelada axiológicamente).

Desde el punto de vista filosófico, el pensador español José Ortega y Gasset, nos había invitado a pensar la crisis de la sociedad europea como una sociedad de incertidumbre. En sus análisis, nos dice que la crisis de la sociedad europea actual, -y no sobre decirlo, aunque no sólo ella-, es que no sabe lo que le pasa, y esto es, justamente, lo que nos pasa. En efecto, los seres humanos sin el reconocimiento y cultivo de la dimensión axiológica de la existencia, no sólo carecen de la motivación necesaria para vivir, sino que además, sin esta orientación, se pueden convertir en unos superdepredadores capaces de acabar hasta con sus propias posibilidades de vida.

En estas condiciones, como decimos coloquialmente en Colombia, "si la persona (aquí la sociedad) no sabe para dónde va, entonces, cualquier Bus (medio de transporte público) le sirve”. Si la humanidad, como comunidad de destino planetario (MORIN, 1993), no determina dialogalmente, en las condiciones actuales, sus finalidades propias, entonces no sólo andará errante, sino que al mismo tiempo maximizará sus potencialidades de autodestrucción. No sólo de sí misma, sino del planeta en el que ella habita (JONAS, 1995).

La humanidad no se hará viable, humanamente hablando, única y exclusivamente con la creación de conocimiento tecno-científico, sino que ha de desarrollar otro tipo de conocimiento que le permita hacer un uso razonable del conocimiento científico (POTTER, 1971; 1988). De no ser esto posible, la humanidad como un todo, desaparecerá sobre la faz de la tierra. Todo será cuestión de tiempo.

\footnotetext{
${ }^{6}$ BERGER; KELLNER, 1973 (traducción española: (1979). BERGER, P.; BERGER, B.; KELLNER, 1979. Una buena introducción al asunto planteado por Berger se puede encontrar en: BONETE PERALES, 1990, p. 557-590; y WUTHNOW et al. 1988, p. 17-19; 31-90; $267-291$.
} 
Esto para Corbí y para Nicolescu es una verdadera tragedia. Más aún, la única y verdadera tragedia que tendrá que afrontar la humanidad, si quiere seguir haciéndose viable, en este siglo que ahora comienza.

\title{
2 La propuesta de Marià Corbí: reconocer y cultivar la cualidad humana y la cualidad humana profunda. Hacia una epistemología axiológica
}

\begin{abstract}
El conocimiento ha tenido y tiene que ser científico y por tanto desaxiologizado. De esta manera se produce una necesidad históricamente inédita: la de la construcción explícita de los proyectos axiológicos colectivos en su doble dimensión, relativa (a nuestras necesidades) y absoluta (como si ellas no existieran). Porque sin proyecto axiológico ninguna sociedad es viable, mucho menos la sociedad de conocimiento. $\mathrm{Y}$ digo proyectos, en plural, porque deberán construirse para cada tipo de organización y deberán modificarse conforme la sociedad cambie... En otras palabras: la gestión de la potencia de las ciencias y tecnologías en continuo y rápido crecimiento por su retroalimentación mutua, y la gestión de las transformaciones constantes de las formas de vida de individuos y colectivos provocadas por la continua innovación de productos y servicios, requiere, con urgencia, encontrar maneras adecuadas para cultivar la cualidad humana y la cualidad humana profunda... Sólo desde esa cualidad podrá gobernarse convenientemente la marcha de las sociedades en tránsito y de las sociedades de innovación y cambio constante. De esa cualidad humana depende la supervivencia de nuestra especie, de la vida y de la habitabilidad del planeta. (CORBÍ, 2014, p. 1) 7 .
\end{abstract}

Con la creación e impacto de los conocimientos científico-técnicos en las sociedades de la segunda industrialización o sociedades de conocimiento, la humanidad ha cambiado no sólo la valoración que hace de su conocimiento, sino también la interpretación de la realidad y de sí misma. La humanidad ha pasado de una antropología dual de cuerpo/espíritu, -propia de las sociedades preindustriales o agrarias en las que se originaron las religiones como su invento más creativo-, a una antropología bio-cultural que retorna al hombre a su nicho biológico, pero conservando, de otra manera, los fenómenos humanos profundos a los que se hacía alusión desde una antropología dual con el término espiritualidad. El hombre actual continuará siendo espiritual. Pero, la espiritualidad no es un fenómeno

\footnotetext{
${ }^{7}$ Los paréntesis son míos.
} 
propio del espíritu contrapuesto a la materia, sino la sutilización de las capacidades cognoscitivas en un sentido amplio.

Desde una nueva antropología, los humanos no son un compuesto de materia/espíritu, sino unos animales muy raros: unos animales que hablan. Y hablando pueden programar cultural y lingüísticamente lo que ha quedado indeterminado desde su condición biológica. Todos los animales tienen programada genética y morfológicamente la manera de hacerse viables: su manera de sobrevivir. Los humanos son los únicos animales que carecen de dicha determinación genética y morfológica. Por tanto, tienen que culminar su indeterminación biológica programando culturalmente todos los cómos de su existencia. El mecanismo a partir del cual los humanos se programan, es decir se autodeterminan en aquello que quieren ser, es entonces, el habla.

¿Por qué y cómo los humanos pueden programarse (determinarse en lo que son) desde el mecanismo bio-cultural del habla? Porque por este recurso biocultural, el modo de vida deja de ser como para el resto de animales, binario, para convertirse en un modo de vida ternario. En los animales no-humanos, su forma de vida es binaria: de un lado un sujeto de necesidades; y de otro lado, un campo dónde satisfacer dichas necesidades. La interpretación del medio se hace a partir de las determinaciones genético-morfológicas. En los animales no-humanos, el medio circundante o entorno es lo que interpretan sus necesidades genética y morfológicamente determinadas y no hay otra opción.

En los animales que hablan, es decir en los humanos, la viabilidad es ternaria: de un lado un sujeto de necesidades (todo animal lo es, y los humanos no son una excepción), en parte determinado genético-morfológicamente; de otro lado, un campo dónde satisfacer dichas necesidades (medio circundante que los humanos interpretan a través del habla como realidad); y. en tercer lugar, un recurso desde el cual interpretar esa realidad desde las necesidades de supervivencia: el habla. 
A diferencia del resto de los animales, el campo dónde satisfacer las necesidades queda adscrito a la significación lingüística que se hace del mismo, y de esta manera el entorno o medio circundante queda convertido en realidad. La realidad, es entonces lo que se interpreta lingüísticamente a partir de un sujeto de necesidades que habla. Pero, la realidad no puede reducirse a la interpretación lingüística que se hace de ella de cara a la supervivencia. La realidad no es solamente la interpretación que hace del entorno o medio circundante de cara a la satisfacción de necesidades, sino también aquello otro que no cabe ni puede caber nunca en dichas interpretaciones. Si no fuera así, los humanos perderían su más originaria manera de ser, no podrían programarse y quedarían encerrados, como el resto de los animales, en una interpretación del medio circundante desde sus características genético-morfológicas.

Esto no significa que se tenga que excluir del espectro del conocimiento de la realidad, aquellos fenómenos que en la antropología dual de cuerpo/espíritu se llamaban espirituales, sino que ahora se los puede encuadrar en las condiciones bio-culturales de los animales que hablan. En este sentido, la realidad es primariamente para el ser humano, la significación del entorno a partir del mecanismo bio-cultural del habla. La realidad, es lo que nos dice nuestra interpretación lingüística del entorno o medio circundante, y desde dicha interpretación lingüística, los humanos completamos nuestra indeterminación genética con el objetivo primario de hacernos viables.

Pero, -y esto es lo fundamental-, al mismo tiempo que interpretamos la realidad desde el recurso bio-cultural del habla, el habla nos permite distinguir entre la realidad significada y lo real que está ahí, lo que no cabe en nuestras consideraciones lingüísticamente mediadas (lo sagrado en la perspectiva nicolesquiana, como veremos a continuación). De tal manera que la realidad es a un mismo tiempo la significación lingüísticamente mediada que hacemos del medio circundante de cara a la satisfacción de necesidades, y lo in-conmensurable, lo in-decible, lo in-abarcable para la racionalidad lingüísticamente mediada. En 
este sentido, nos dice Corbí, la realidad es ab-soluta: no depende de nosotros. Pero, la podemos modelar para movernos en ella y para poder sobrevivir.

Durante muchísimo tiempo - y esto es lo que se nos está haciendo cada vez más explícito en nuestras actuales sociedades del conocimiento -, los humanos que vivieron (y viven) en modos de vida estáticos, identificaron la dimensión in-decible de la realidad con el modelamiento que se tenía que hacer de ella para sobrevivir, y pensaron que con el lenguaje se conocía y se describía la realidad tal y como ella era. Esto es la que Corbí llama epistemología mítica, en un sentido no peyorativo o ilustrado, sino un sentido antropo-lingüístico.

Durante muchísimo tiempo los humanos creyeron que la realidad mundana y extramundana que se les hacía presente a partir de la mediación lingüística, les hablaba y les revelaba sus secretos. Los humanos, en este sentido, creyeron que podían conocer la realidad tal y como ella era a partir del filtro lingüístico que se utilizaba para interpretarla. Y aunque metafóricamente se puede seguir diciendo que la realidad nos habla, hoy sabemos (y esto es lo propio de una epistemología no-mítica), que el lenguaje humano ni describe, ni revela la realidad, sino que tan sólo la modela, la significa, con fines de sobrevivencia. Pero, insistamos una vez más, la realidad no es sin más, la interpretación lingüísticamente mediada que hacemos de ella desde nuestras necesidades de supervivencia.

Ahora bien, si la característica más propia de los humanos consiste en ser vivientes culturales, es decir, en ser animales que hablan y que modelan la realidad para hacerse viables. $\mathrm{Y}$ al mismo tiempo sabemos que la interpretación lingüísticamente mediada no agota en su significado lo que sea la realidad, entonces podemos afirmar que la cualidad humana específica consiste en tener un doble acceso a la realidad: un acceso primario determinado por las necesidades, temores, deseos, intereses y expectativas de supervivencia, que se modelan lingüísticamente y un acceso ab-soluto, último, desegocentrado que silencia la interpretación lingüística que se debe hacer de la realidad de cara a la sobrevivencia. 
En el primer caso, hablamos de un conocimiento egocentrado y lingüísticamente mediado de la realidad que es necesario, apto y útil para sobrevivir. Este conocimiento determina lo que Corbí llama nuestra cualidad humana. En el segundo caso, hablamos de un conocimiento desegocentrado, silencioso en tanto que no se queda atrapado a través de ninguna forma (formulación lingüística). Es un conocimiento gratuito, ab-soluto, interesado incondicionalmente por la realidad, que no sirve para nada práctico puesto que no nace desde los intereses inmediatos de sobrevivencia, y sin embargo, determina nuestra manera humana de ser. Este conocimiento constituye lo que Corbí (2010) llama nuestra cualidad humana profunda. A este tipo de conocimiento fue al que en los modos socio-laborales y culturales de vida preindustrial o estática, bajo una comprensión dual de la existencia y desde una interpretación mítica del conocimiento y de la realidad, se le llamó Espiritualidad.

A través de este tipo de conocimiento, el animal que habla puede acceder de manera explícita e incondicional a la dimensión última, ab-soluta o teologal de la existencia (OSORIO 2014d, p. 150-200). El animal que habla, puede entrar en comunión con el misterio in-sondable e in-decible que le constituye. El humano puede asumir la actitud de un testigo que se conmociona y que vibra con la inmensidad de lo real de la cual él mismo es y hace parte.

La epistemología axiológica, quiere dar razón de este doble acceso a la realidad y quiere mostrar que el conocimiento silencioso ésta (cualidad humana profunda -antigua espiritualidad-), no es el conocimiento de otra realidad, sino de esta misma realidad cuando se accede a ella sutilizando nuestras competencias cognoscitivas. Esto, de cara a una sociedad de conocimiento - que se empecina en quedar atrapada en un conocimiento lingüísticamente mediado, jalonado por el interés de lucro y de rentabilidad -, se convierte en una alternativa para la construcción de modos socio-culturales de vida, que puedan direccionar de otra manera los progresos científico-técnicos. De no desarrollar este saber amplio en medio de las sociedades de conocimiento, la humanidad, según Corbí, como um todo, no podrá hacerse humanamente viable. La humanidad, como nos lo dice 
Berger (1979), continuará naufragando en un “Mundo sin hogar”. Sólo que aquí lo que se hunde no es un Titanic, sino la humanidad entera en su nueva condición de humanidad planetaria.

La cualidad humana es el cultivo explícito del conocimiento de la dimensión relativa y absoluta de la realidad, es decir de nuestra cualidad humana específica en tanto que vivientes culturales; la cualidad humana profunda es cultivo incondicional del conocimiento de la dimensión absoluta de la realidad. Este cultivo fue llamado desde una antropología dualista de cuerpo/alma: Espiritualidad, Mística, Religión. El cultivo de ambas cualidades es una condición de posibilidad de nuestra condición de hablantes (animales que hablan). Y su cultivo explícito es una posibilidad que se desprende en las sociedades de conocimiento. Y de no cultivarlo, de manera explícita, no podremos garantizar nuestra viabilidad como especie. (CORBÍ, 2014, p. 1).

A la fecha, la epistemología axiológica se ha venido implementando desde la metodología de IDS, es decir del Interés (I) incondicional por las personas y las cosas; por el Desapego (D) de las estructuras egocentradas del yo como centro de interés para comprender la realidad, y desde el silenciamiento (S) total de las formas lingüísticamente mediadas del conocimiento de la realidad, para acceder finalmente a un conocimiento no-dual de la dimensión absoluta de la realidad que somos y nos constituye: "momento" máximo de la espiritualidad que coincide con una comprensión desegocentrada de la realidad (CORBí, 2013c, p. 310-321; 2013d, 227-304).

IDS, luego de muchos ires y venires y de su implementación permanente durante años, continuará su cometido para el cultivo de la cualidad humana profunda teniendo en cuenta que éste en las sociedades de conocimiento, ha de presentarse como una Indagación libre en la perspectiva dialogal y Comunicativa en el horizonte del Servicio, ICS. En síntesis, la epistemología axiológica se hace viable a partir de IDS como ICS (CORBÍ 2013d, p. 227-30o). 


\section{La transdisciplinariedad como medio para superar la escisión entre la cultura tecno-científica y la cultura espiritual. (Cfr. NICOLESCU, 2004).}

Un humanismo postmoderno desconectado de lo sagrado no tiene ninguna posibilidad de sobrevivir en el marco de la reciente, fuerte e irracional cultura tecno-científica. (NICOLESCU, 2004, p. 140).

Para Nicolescu, al comienzo de la humanidad se encontraban unidas la ciencia, la cultura y la espiritualidad. El desarrollo de aquellas estuvo animado por las preguntas sobre el significado de la vida y del universo.

El germen de división entre ellas se dio en el siglo XVII con la implementación de la metodología de las ciencias positivas, que se convirtió en regla para la construcción del conocimiento en el siglo XIX, y que tuvo su culminación en el siglo XX mediante la escisión radical entre la cultura científica y la cultura humanística (SNOW, 1980).

Pero, la situación no para allí. Muy recientemente se ha dado un nuevo matrimonio entre un tipo de ciencia, herméticamente separada de la cultura, y la tecnología, que convirtiéndose en el motor del sistema económico ha dado origen a lo que hoy se conoce con el nombre de tecno-ciencia:

El matrimonio entre la ciencia fundamental y la tecnología se logra ahora, generando una cultura tecno-científica que conduce a la enorme fuerza irracional de la globalización, centrada en la economía, que a su vez podría borrar todas las diferencias entre culturas y entre las religiones. Parte de la cultura humanística ya ha sido absorbida en la cultura tecno-científica. (NICOLESCU, 2004, p. 145).

Esto significa que la organización actual del aparato tecno-científico de producción económica, desde los intereses de lucro y explotación comercial, conlleva al surgimiento de problemas fundamentales que afectan la vida y la muerte no sólo de los humanos, sino también de la biosfera del planeta.

De esta manera, llegamos a una situación en la que por un lado, está la cultura tecno-científica producto de la unión de la cultura científica con el máximo interés de lucro, vía tecnología. Y por otro lado, y frente a ella, la cultura espiritual, 
que es una constelación de modos de ver el mundo sin los imperativos tecnoeconómicos, pero que están siendo colonizados para aquellos. Para Nicolescu, los miembros de la cultura tecno-científica tienen la responsabilidad insoslayable de integrar estos saberes en un nuevo modelo epistemológico y ontológico, para beneficio de una nueva racionalidad científica, y como antídoto para la autodestrucción de la humanidad. Ahora bien, ¿Cómo puede hacerse posible dicha integración?

Si insistimos, nos dice Nicolescu, en los aspectos desenfrenados de la tecnociencia no habrá posibilidades de integración. Pero, además, posiblemente tampoco queden condiciones de posibilidad para la vida misma en el planeta. Por tanto, la única vía es adentrarse en los “axiomas” fundamentales del conocimiento científico para superarlos, y así crear unas nuevas condiciones racionales que puedan posibilitar un diálogo entre la cultura tecno-científica y la cultura espiritual. La transdisciplinariedad es, en este sentido, un dispositivo para posibilitar el diálogo entre la cultura tecno-científica y la cultura espiritual.

Sólo si se descubre el espacio que está entre, a través y más allá de las disciplinas fragmentadas del conocimiento, se podrán establecer vínculos entre las dos culturas pos-modernas, integrando la ciencia y la sabiduría. Sólo si se logra la integración entre la cultura tecno-científica (ciencia) y la cultura espiritual (sabiduría) se podrá desarrollar una nueva espiritualidad que nos salve de la autodestrucción.

La transdisciplinariedad puede ofrecer un nuevo marco metodológico para el diálogo entre la cultura tecno-científica y la cultura espiritual. 


\subsection{Del conocimiento disciplinar, pasando por el multi, pluri, poli e interdisciplinar al conocimiento transdisciplinar 8}

Para Nicolescu (Nicolescu, 1996) la disciplinariedad es la organización del conocimiento científico a partir de campos o áreas especializadas del saber. Las disciplinas dan razón del conocimiento de las partes de un todo, que por su inmensidad, se hace imposible de comprender como todo. Descartes, con sus reglas para guiar el espíritu hacia un saber verdadero e indubitable, es el gran fundador de este tipo de mentalidad.

La multi-poli o pluridisciplinariedad, así como la interdisciplinariedad tienen en común la búsqueda de un conocimiento que está más allá de las disciplinas. Pero, con la limitación de no poder salirse del marco de conocimiento disciplinar. Se piensa que con la sumativa de los conocimientos fragmentados, se puede ir más allá de las partes y de alguna manera se puede conocer el todo. Pero, la situación actual es muy otra, las 10.000 disciplinas que compiten por el conocimiento fragmentado de la Realidad, nos lo demuestran.

La transdisciplinariedad, hunde sus raíces en los conocimientos uni, poli, multi e interdisciplinares. Pero, va más allá de ellos posibilitando una nueva comprensión ontológica y epistemológica del conocimiento y de la Realidad. Es una apuesta por comprender la realidad que somos y nos constituye, cuando han sido puestos en paréntesis los criterios demarcatorios del conocimiento en disciplinas y cuando la Realidad ya no es vista como un “objeto" que está al frente de un "sujeto" y que se puede conocer de manera determinista y valorativamente neutra, sino como un sistema abierto multinivelado, multidimensional, y multireferencial.

La transdisciplinariedad, se dirige, como el prefijo 'trans' indica, a lo que está a la vez entre, a través y más allá de toda disciplina. Su objetivo o finalidad es la comprensión del mundo actual, donde uno de sus imperativos es la unidad del conocimiento. (NICOLESCU, 1996, p. 38).

\footnotetext{
${ }^{8}$ Cita escondida para la neutralidad del lector.
} 


\subsection{La metodología transdisciplinar}

Nos dice Nicolescu que después de muchos años de trabajo en el ámbito de la física de partículas, llegó a la formulación de los tres postulados (axiomas en el lenguaje de la ciencia clásica) básicos de metodología transdisciplinar: el postulado ontológico, el postulado lógico y el postulado epistemológico9. Estos tres nuevos postulados, que surgen en diálogo con los axiomas de la ciencia clásica, rezan de la siguiente manera:

- (El) Postulado ontológico: (nos dice que) existen en la naturaleza y en nuestro conocimiento de la naturaleza, diferentes niveles de Realidad y correspondientemente, diferentes niveles de percepción de la Realidad.

- (El) Postulado lógico: (nos dice que) El paso de un nivel de Realidad a otro es asegurado por la lógica del tercero incluido.

- (El) Postulado epistemológico: (nos dice que) la estructura de la totalidad de niveles de Realidad y de percepción de la Realidad, es una estructura compleja: cada nivel es lo que es porque todos los niveles existen al mismo tiempo.

Los dos primeros axiomas obtienen su evidencia experimental de la física cuántica, pero van bastante más allá de las ciencias exactas. El último, tiene su fuente no sólo en la física cuántica, sino además en una variedad de otras ciencias exactas y humanas. Los tres han estado, de acuerdo al pensamiento tradicional, presentes en la Tierra desde el inicio de los tiempos. (NICOLESCU, 2006, p. 23). ${ }^{10}$

\subsubsection{Postulado ontológico}

El postulado ontológico tiene que ver primariamente con aquello que Nicolescu, amparado en la tradición del conocimiento físico, llama Realidad y niveles de la Realidad y estos a su vez con la manera en que se ha establecido la relación entre el objeto y el sujeto de conocimiento. Por ello, y antes de entrar en la dilucidación de los postulados, voy a hacer una contextualización de las maneras como en occidente hemos entendido las relaciones entre el objeto y el sujeto del conocimiento, y al mismo tiempo, me detendré a explicitar la definición

\footnotetext{
${ }^{9}$ Los postulados, no son teoremas. Por tanto no necesitan demostración. Los postulados, tal y como se procede en ciencia adquieren su validez por los resultados de sus aplicaciones. Si los resultados están en contradicción con los hechos experimentales, aquellos han de ser modificados o sustituidos.

${ }^{10}$ Los paréntesis son míos.
} 
epistemológica y ontológica del término Realidad, tal y como se usa en la perspectiva Nicolesquiana.

En la historia de la filosofía, la relación entre el sujeto y el objeto del conocimiento ha sido un problema fundamental. La relación varía según los enfoques filosóficos, así como los momentos históricos y culturales. Nicolescu (2012) propone analizar dicha relación a través de cuatro maneras diferenciadas: a) la manera pre-moderna en la que el sujeto queda determinado por el objeto; b) la manera moderna en la que el sujeto y el objeto se quedan uno frente al otro desde una ontología previamente constituida; c) la manera posmoderna en la que la relación se diluye a favor del sujeto; y d) la suya propia en la que la relación binaria sujeto-objeto se convierte en una relación ternaria: sujeto-tercero incluido-objeto al interior de una naturaleza que se presenta para nuestro conocimiento en forma multidimensional, multireferencial y polinivelada. Gráficamente podríamos representar las distintas concepciones de la relación sujeto/objeto de la siguiente manera (Ver gráfica No. 1):

\section{Gráfica 1: Relación Sujeto/objeto en la historia de la filosofía}

\section{Relación Sujeto/Objeto en la Pre-Modernidad}

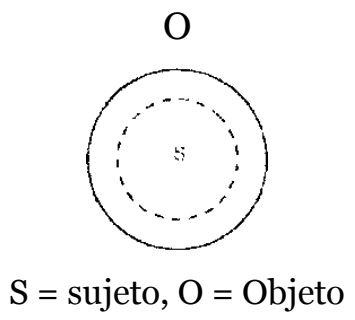




\section{Relación sujeto/objeto en la Modernidad}

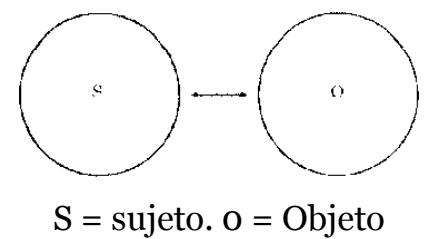

\section{Relación Sujeto/objeto en la Post-Modernidad}
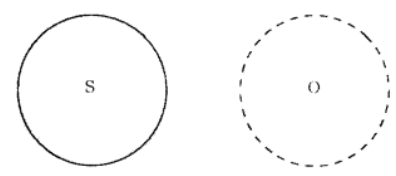

$$
\mathrm{S}=\text { Sujeto } \mathrm{O}=\text { Objeto }
$$

\section{Relación Sujeto - tercero incluido- Objeto en el conocimiento transdisciplinar}

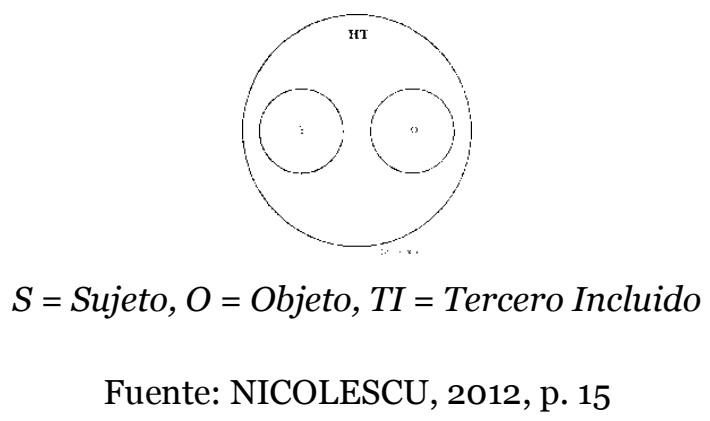

Como se dijo anteriormente, la clave para la comprensión de la relación objeto-sujeto de conocimiento es la visión de la Realidad que los humanos comparten en diferentes periodos históricos y culturales. Según Wolfang Pauli premio Nobel de Física del siglo pasado, "Cuando el hombre común dice 'realidad', él piensa que esto es algo obvio. Pero, para mí, la formulación de una nueva idea de la realidad es la más importante y la tarea más difícil de nuestro tiempo" (citado por NICOLESCU, 2012, 14). 
Con el fin de centrar la radicalidad del postulado ontológico, Nicolescu (2012) define la Realidad en el sentido que está siendo utilizado hoy por los físicos cuánticos, es decir, en términos de la "resistencia".

Por 'Realidad' pretendo ante todo designar aquello que se resiste a nuestras experiencias, representaciones, descripciones, imágenes, o incluso formulaciones matemáticas. Se pone el acento en una visión relacional de lo que la 'Realidad' podría significar. En la medida en que la Realidad participa en el ser del mundo, uno tiene que asignar también una dimensión ontológica a este concepto. La Realidad no es únicamente una construcción social, el consenso de una colectividad o un acuerdo intersubjetivo. También tiene una dimensión trans-subjetiva. El significado que le damos a la palabra 'Realidad' es, por tanto, pragmático y ontológico al mismo tiempo. En consecuencia, voy a denotar esto por una letra Mayúscula esta palabra. (NICOLESCU, 2012, p. 14).

Por contraste con la forma de comprender la Realidad en términos pragmáticos y ontológicos, Nicolescu (2012) hace una diferenciación entre la Realidad y lo Real.

Lo Real designa lo que es, mientras que la Realidad está conectada a la resistencia en nuestra experiencia humana. Lo 'Real' nos está, por definición, velado para siempre (no tolera ninguna cualificación nuestra), mientras que la 'Realidad' es accesible a nuestro conocimiento. Lo Real implica no-resistencia, mientras Realidad implica resistencia. (p. 14).

Teniendo en cuenta estas definiciones, el enfoque transdisciplinario del conocimiento y de la Realidad, va a sostener que existen diferentes niveles de Realidad y consecuentemente diferentes niveles de percepción de la Realidad. Este es el postulado ontológico del conocimiento transdisciplinar.

Un nivel de Realidad, es un conjunto de sistemas que son invariantes pero sólo bajo ciertas leyes. Así, por ejemplo, las entidades cuánticas, son entidades cuánticas en tanto que están subordinadas a las leyes cuánticas, que son leyes que aplican de manera específica para el mundo microfísico. Un nivel de Realidad se decide acorde a leyes que determinan su conocimiento y cuando se pasa de un nivel de Realidad a otro nivel de Realidad se presenta una discontinuidad, un 
rompimiento que equivale a un cambio en las leyes, y también en los conceptos fundamentales que son aplicables a dicho nivel de Realidad.

Cada nivel de Realidad tiene su espacio-tiempo asociado, diferente de un nivel al otro. Por ejemplo, el realismo clásico está asociado con 4 dimensiones espacio-tiempo (tres dimensiones de espacio y una dimensión de tiempo), mientras que el realismo cuántico se asocia con el espacio-tiempo cuyo número de dimensiones es mayor que cuatro. (NICOLESCU, 2006, p. 25).

La representación simbólica tanto de los niveles de Realidad, como de los niveles de percepción de la Realidad es el siguiente.

$$
\left\{N R n, \ldots, N R_{2}, N R_{1}, N R_{o}, N R_{-1}, R N_{-2}, \ldots, N R-n\right\}
$$

Representación simbólica de los niveles de la Realidad y de percepción de la Realidad Fuente: NICOLESCU, 2012, p. 16

En la parte izquierda son simbólicamente representados los niveles de la Realidad. El índice $\mathrm{N}$ puede ser finito o infinito. En la parte derecha son simbólicamente representados los niveles de percepción de la Realidad. El índice $\mathrm{N}$ puede ser finito o infinito.

El postulado ontológico de la existencia de los niveles de la Realidad permite comprender que en la Realidad hay o se da una estructura multinivelada, pluridimensional y multireferencial que conserva su unidad plural en medio de una estructura abierta. Es decir, introduce un nuevo principio de relatividad en el que ningún nivel de Realidad se constituye en lugar privilegiado para acceder a la Realidad y en el que un nivel de Realidad es lo que es porque todos los demás niveles de Realidad existen al mismo tiempo.

Cada nivel se caracteriza por su carácter incompleto, las leyes que rigen este nivel son sólo una parte de la totalidad de las leyes que rigen todos los niveles. E incluso la totalidad de las leyes no agotan la totalidad de la Realidad. También tenemos que considerar el Sujeto y su interacción con el objeto. El conocimiento es siempre abierto. (NICOLESCU, 2012, p.17). 
La existencia de los niveles de la Realidad había sido confirmada por diferentes tradiciones culturales y espirituales de la humanidad, pero su existencia se fundamentaba, como no podía ser de otra manera, en los dogmas religiosos o en la exploración interior del ser humano. Hoy podemos comprenderla y validarla desde el punto de vista epistemológico y científico ${ }^{11}$.Otra forma de representar los niveles de Realidad sería el siguiente (Ver gráfica No. 2):

\section{Gráfica 2: Niveles de Realidad}

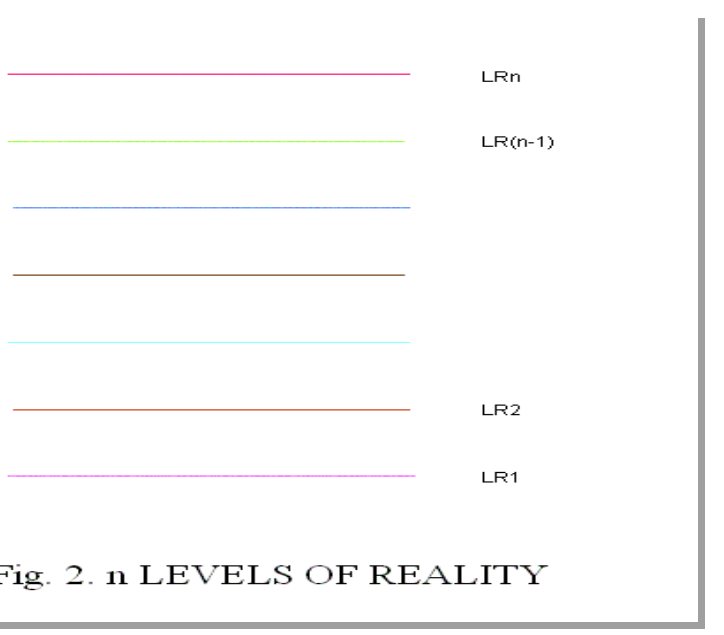

Fuente: NICOLESCU, 2011b -ppt-

\subsubsection{El postulado lógico.}

El postulado lógico, nos dice que el paso de un nivel de Realidad a otro, está asegurado por la lógica del tercero incluido. Así, entre dos términos contradictorios, por ejemplo entre A (onda) y no-A (partícula), existe un tercer término que hace las veces de mediador y que permite comprender la Realidad más

\footnotetext{
${ }^{11}$ La comprensión de la naturaleza a partir de niveles de Realidad no es, de hecho, un dato nuevo. En el ser humano desde siempre, como lo atestiguan las tradiciones religiosas y espirituales de la humanidad, se dan por lo menos dos dominios de la realidad: uno visible y manipulable y otro invisible e impenetrable. Como vimos en el numeral 1, la epistemología axiológica, desde una fundamentación antropo-lingüística del conocimiento, nos dice que el ser humano tiene un doble acceso a la realidad: un acceso relativo y acceso absoluto. Por los presupuestos utilizados la epistemología axiológica no se refiere a varios niveles de Realidad, pero deja en claro que se puede acceder a ella en por lo menos dos niveles.
} 
allá del principio clásico de no-contradicción y del tercero excluido ${ }^{12}$. El postulado lógico del tercero incluido $\mathrm{T}$, queda completamente aclarado una vez que la noción de niveles de Realidad se ha hecho presente.

Con el fin de obtener una imagen clara del significado del tercero incluido, voy a representar los tres términos de la nueva lógica (A, no-A, y T) y la dinámica asociada a ella, tal y como lo hace Nicolescu, es decir, a través de la figura de un triángulo en el que uno de los vértices (T) se encuentra en un nivel de la Realidad y los dos otros vértices en otro nivel de Realidad (ver Gráfica No. 3).

\section{Gráfica 3: Acción lógica del tercero incluido}

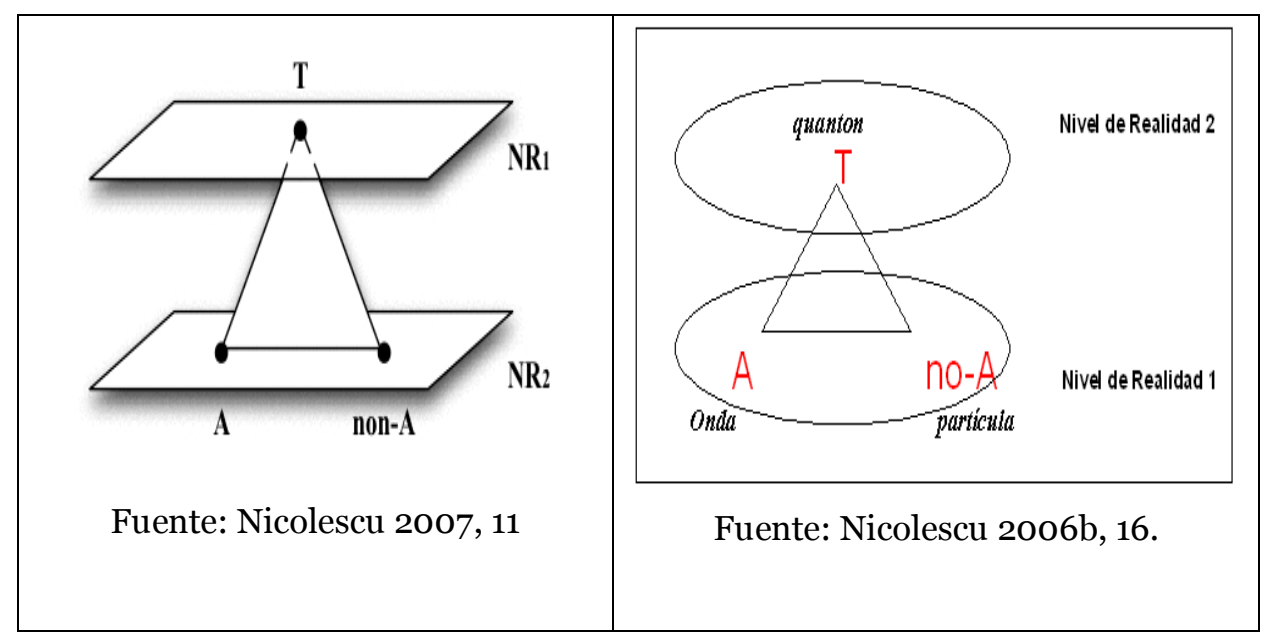

\footnotetext{
${ }^{12}$ Desde la aparición de la mecánica cuántica, la interpretación de la naturaleza física del universo, se ha visto permanentemente sometida a una pareja de contradictores mutuamente excluyentes que se interpretó a partir de la estructura de la lógica clásica que tiene los siguientes tres axiomas: 1 . El axioma de la identidad, que nos dice que $A$ es $A ; 2$. El axioma de la no-contradicción que nos dice que $A$ es no-A; y 3 . El axioma del tercero excluido que nos dice que no hay un tercer término $T$ ( $T$-tercero incluido-), que esté a la vez $A$ y no-A. Después de haberse constituido la mecánica cuántica, en los años treinta, se hizo necesario la construcción de una nueva relación lógica que ampliando el segundo axioma (el de no-contradicción) dio origen a lo que hoy llamados lógicas polivalentes, es decir lógicas que incluyen más de dos valores de verdad. Stéphane Lupasco, según la interpretación de Nicolescu, fue el único que puso su atención en el tercer axioma, a tal punto que lo transformó en su contrario. Lupasco demuestra que hay un axioma lógico que es formalizable, formalizado, multivalente (con tres valores A, no-A y T) y no-contradictorio: este es el axioma, principio o postulado lógico del tercero incluido, que se comprende bastante bien con la introducción de los diferentes niveles de Realidad en la naturaleza y en sujeto que conoce la naturaleza, como veremos a continuación: "Después de la constitución definitiva de la mecánica cuántica, en los años treinta, los fundadores de la nueva ciencia han tenido un problema agudo en la construcción lógica de la realidad. Siguiendo el trabajo de Birkhoff y Von Neumann, una cosecha entera de la lógica cuántica no se hizo esperar. La mayoría de las lógicas cuánticas cambiaron el segundo axioma de la lógica clásica -el axioma de no-contradicción- e introdujeron varios valores de verdad en lugar del par binario ( $A$, y no-A). Estas lógicas multivalentes no tuvieron en cuenta otra posibilidad: la modificación del tercer axioma -el axioma del tercero excluido. El futuro dará crédito histórico a Lupasco por haber demostrado que la lógica del tercero in cluido es una verdadera lógica, formalizable y formalizada, multivalente (con tres valores: A, no-A y T) y no contradictoria. La comprensión del axioma del tercero incluido - hay un tercer término $T$ que es a la vez $A$ y no-A - se esclarece por completo cuando se introduce el concepto de 'niveles de Realidad'”' (NICOLESCU, 1999, p.2).
} 
El término medio, es de hecho, el tercero incluido. Si uno se mantiene en un solo nivel de Realidad, toda manifestación aparece como una lucha entre dos elementos contradictorios. La tercera dinámica, la del estado de $\mathrm{T}$, se ejerce en otro nivel de la Realidad, donde lo que parece estar desunido está, de hecho unido, y lo que parece contradictorio es percibido como no-contradictorio. En otras palabras, la acción de la lógica del tercero incluido en los diferentes niveles de Realidad es capaz de explorar la estructura abierta de la unidad de los niveles de Realidad. (NICOLESCU, 2008b, p. 15)

En este nuevo enfoque, no sólo se puede comprender que existen niveles de Realidad, sino que al mismo tiempo se descubre que cada nivel de Realidad, así concebido, es incompleto. Las leyes que rigen un nivel de Realidad, son parte de la totalidad de las leyes que rigen la Realidad. Pero no sólo eso, sino que además no hay un nivel de Realidad desde el cual se pueda acceder de manera privilegiada a la totalidad de la Realidad.

Así las cosas, el conocimiento que podemos tener de la Realidad en sus niveles y en su totalidad, será siempre incompleto: el conocimiento humano tiene una estructura abierta. No es posible una super-ciencia que dé cuenta de todos los niveles de la Realidad, ni que pueda subsumir un nivel de Realidad desde otro nivel jerárquicamente superior. Una teoría unificada y cerrada de la ciencia es, simplemente imposible. ¿Significa esto que el conocimiento de la Realidad es caótico o anarquista? No necesariamente. Para Nicolescu la autoconsistencia (coherencia lógica) de la totalidad de los niveles de Realidad presupone una zona de no-resistencia para nuestro conocimiento. Esta zona es la zona de no-resistencia a nuestras experiencias, representaciones, descripciones, imágenes y fórmulas matemáticas. Esta zona de no-resistencia es la que se hace evidente a través del principio ontológico del tercero incluido.

La zona comprendida entre dos niveles de Realidad diferentes y más allá de todos los niveles de Realidad, es una zona de la transparencia, la zona de no-resistencia a nuestras experiencias, representaciones, descripciones, imágenes y formulaciones matemáticas. En pocas palabras, la transparencia de esta zona se debe a las limitaciones de nuestros cuerpos y de nuestros órganos de los sentidos -limitaciones que se aplican independientemente de lo que las herramientas de medición puedan extender la percepción de los órganos de los sentidos-. (NICOLESCU, 2008a, p. 512). 
Para Nicolescu el ensamblaje de todos los niveles de la Realidad y su zona complementaria de la no-resistencia, constituye el Objeto transdisciplinario (NICOLESCU, 2008a, p. 512)13. (Ver gráfica No. 4).

\section{Gráfica 4: Objeto transdisciplinario}

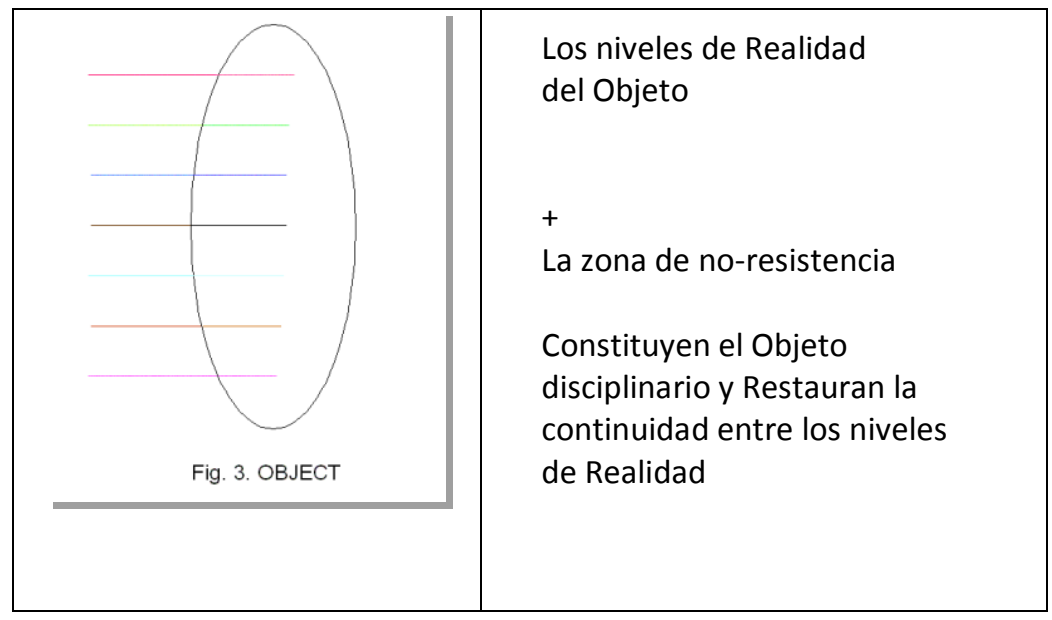

Fuente: NICOLESCU, 2011 b -ppt-.

Esta comprensión del Objeto Transdisciplinario, no afecta sólo a lo que en la epistemología clásica llamábamos el "objeto" del conocimiento de la Realidad (El conocimiento de un único nivel de Realidad o el conocimiento de fragmentos de un nivel de Realidad), sino que también afecta al "sujeto" que conoce dicho nivel de Realidad.

Nicolescu (2011a) inspirado en la fenomenología de Edmund Husserl, afirma que el sujeto transdisciplinario comprende la Realidad a través de niveles de Realidad del sujeto que están potencialmente presentes en nuestro ser. Al igual que los niveles de Realidad del objeto, los niveles de la Realidad del Sujeto presuponen, una zona de no-resistencia a la percepción. A los niveles de percepción de la

\footnotetext{
${ }^{13}$ Las negrillas son mías.
} 
Realidad del Sujeto más la zona de no-resistencia a la percepción, se le denomina Sujeto Transdisciplinario.

Los diferentes niveles de Realidad del Objeto son accesibles a nuestros conocimientos gracias a los diferentes niveles de percepción que están potencialmente presentes en nuestro ser. Estos niveles de percepción permiten una cada vez mayor visión general, unificadora y abarcadora de la Realidad, sin que ella se agote totalmente. De una manera rigurosa, estos niveles de percepción son, de hecho, los niveles de Realidad del Sujeto. La unidad de los niveles de la Realidad del Sujeto y su zona complementaria de no-resistencia, constituye lo que llamamos el Sujeto transdisciplinario. (NICOLESCU, 2008a, p. 512) (Ver gráfica No. 5).

\section{Gráfica 5: Sujeto transdisciplinario}

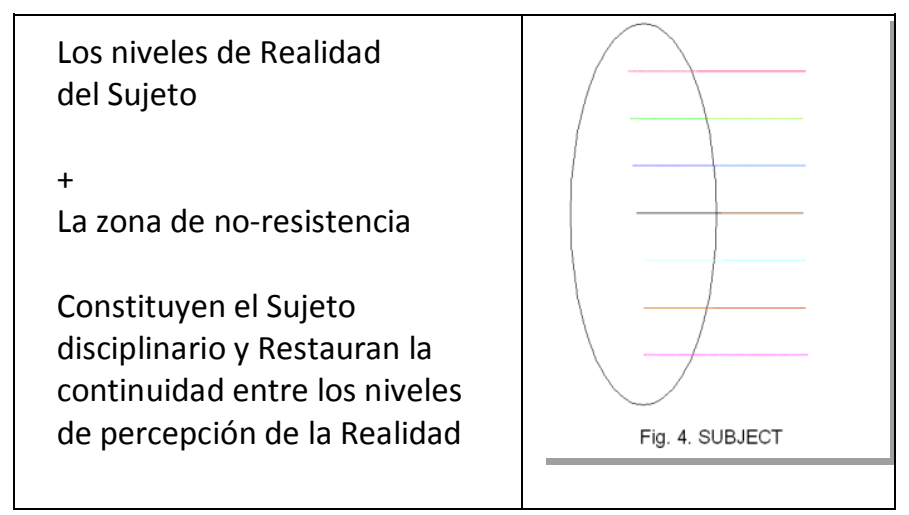

Fuente: NICOLESCU 2011b -ppt-.

La zona de no-resistencia del Objeto Transdisciplinario y la zona de noresistencia del Sujeto Transdisciplinario, deben ser idénticas para que pueda darse una comunicación entre ellas. Esta convergencia isomórfica entre los niveles de Realidad y los niveles de percepción de Realidad, es lo que propiamente constituye en la perspectiva transdisciplinar el conocimiento. Por tanto, el conocimiento humano no es ni exclusivamente objetivo, entendiendo por tal el conocimiento de la Realidad con exclusión del sujeto; ni exclusivamente subjetivo, entendiendo por tal el conocimiento de un Sujeto con independencia de la Realidad, sino que el conocimiento humano es a un mismo tiempo objetivo y subjetivo. El tercero incluido no es un conocimiento. Pero, posibilita la interacción isomórfica para el conocimiento humano. 
En este nuevo contexto, el principio lógico del tercero excluido en la ciencia clásica y que funciona para un único nivel de Realidad, es superado por el principio ontológico del tercero incluido, que no niega la contradicción que se da en un mismo nivel de Realidad, pero la supera cuando se ve la mira desde un nuevo nivel de Realidad. El tercero ontológicamente incluido distingue al mismo tiempo que relaciona los distintos niveles de Realidad en su relación con los distintos niveles de percepción de la Realidad. Esto es absolutamente novedoso y sorprendente en la historia del conocimiento humano. La ciencia clásica, tal y como funciona, no admite ni los niveles de Realidad, ni la zona de no-resistencia de la Realidad.

La zona de no-resistencia juega el papel de un tercero entre el Sujeto y el Objeto, un término de interacción que permite la unificación entre el Sujeto transdisciplinario y el Objeto transdisciplinario conservando su diferencia. En lo que sigue voy a llamar a este término Interacción el Tercero lógicamente incluido. (NICOLESCU, 2008a, p.512).

La unidad abierta del conocimiento entre el Objeto transdisciplinario y el Sujeto transdisciplinario, integrada a partir del tercero lógicamente incluido, permite que en un determinado momento de cruce, se interrelacionen los flujos de información que atraviesan los diferentes niveles de Realidad, con los flujos de consciencia que atraviesan los diferentes niveles de percepción de la Realidad.

Los flujos de información y de consciencia se encuentran en un punto X, para asegurar, por lo menos en un punto X, la transmisión de información coherente y de la conciencia en todo el Universo. En cierto sentido, el punto X es la fuente de toda Realidad y de toda percepción. El punto X y sus lazos asociados de información y de conciencia pueden describir el tercero lógicamente incluido del conocimiento transdisciplinario: el término de interacción entre el Sujeto y el Objeto, no puede reducirse desde el Objeto ni desde el Sujeto. Esta partición ternaria \{Sujeto, Objeto, Interacciones radicalmente diferente de la partición binaria \{Sujeto, Objeto\} que define la metafísica moderna. (NICOLESCU, 2008a p.512).

De esta manera, pasamos de la comprensión binaria sujeto/objeto del realismo clásico a una comprensión ternaria para el conocimiento en donde el Objeto Transdisciplinario, el Tercero Incluido y el Sujeto Transdisciplinario son los 
componentes para una nueva interpretación epistemológica y ontológica para el conocimiento y para la de la Realidad (Ver gráfica No. 6).

\section{Gráfica 6: Representación ontológica del conocimiento transdisciplinar}

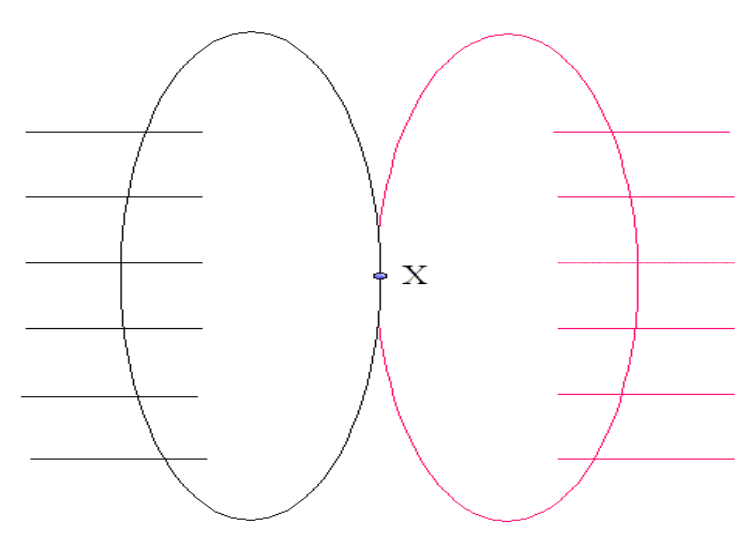

Fig. 5. TD REALITY

Fuente: Nicolescu, 2011b -ppt-

La aparición de al menos tres diferentes niveles de Realidad del objeto en el estudio de los sistemas naturales introducidos por la física cuántica (el nivel macrofísico, el nivel de microfísica y en el espacio-tiempo cibernético (para no hablar de más), es un acontecimiento importante en la historia del conocimiento que le permite a Nicolescu postular de manera analógica por lo menos tres diferentes niveles de percepción de la Realidad para los sistemas sociales: el nivel individual . el nivel comunitario y el nivel planetario (Ver gráfico, No. 7). 


\section{Gráfica 7: Ontología Transdisciplinaria con por lo menos tres niveles de realidad del Objeto y 3 niveles de percepción del Sujeto}

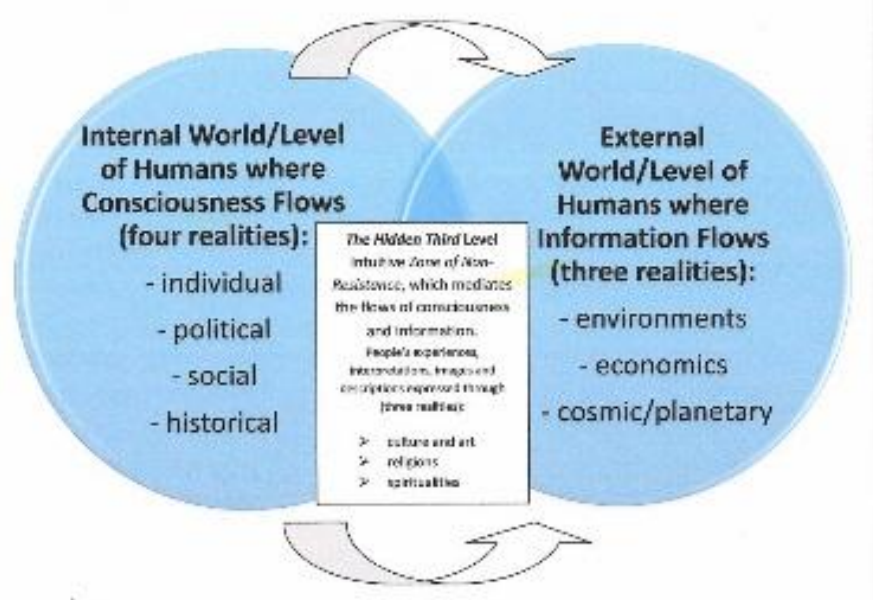

Fuente: MCGREGOR, 2011a, p. 5 .

Desde esta nueva fundamentación abierta e isomórfica del conocimiento humano en a través y más allá de lo niveles de Realidad y de percepción de la Realidad, es donde podemos ubicar el uso de nuestros lenguajes digitales y analógicos junto con lógicas de contradictoria y complementaria reciprocidad:

El encuentro entre los diferentes niveles de Realidad y los diferentes niveles de percepción de la Realidad genera diferentes niveles de representación. Las imágenes correspondientes a un cierto nivel de representación tienen una cualidad diferente a las imágenes asociadas a otro nivel de representación, porque la cualidad de la representación está asociada con un cierto nivel de Realidad y con un cierto nivel de percepción. Cada nivel de representación aparece como un verdadero muro, aparentemente insalvable, debido a su relación con las imágenes generadas por otro nivel de representación. Estos niveles de representación del mundo sensible, están sin embargo relacionados con los niveles de percepción del científico, del artista, o de las personas religiosas. La verdadera creación artística y las experiencias religiosas profundas surgen en el momento en que se crean puentes, entre varios niveles de percepción, cuyo resultado es una transpercepción. La transpercepción permite una comprensión global e indiferenciada de la totalidad de los niveles de percepción. Una creación verdaderamente 
científica surge en el momento que se unen a un mismo tiempo, varios niveles de representación, cuyo resultado es la transrepresentación. (NICOLESCU, 2008a, p.512).14

La transpercepción, así como la transrepresentación pueden explicar, de alguna manera, las sorprendentes similitudes entre los momentos de creación científica y los momentos de creación artística en el ser humano, sin tener que poner en el medio una abismal separación entre el sujeto y el objeto del conocimiento tal y como se pensó en la modernidad.

\subsubsection{Postulado epistemológico o de complejidad}

El postulado epistemológico o de complejidad, nos dice que la estructura de la totalidad de los niveles de la Realidad aparece en nuestro conocimiento como una estructura compleja:

La estructura de la totalidad de los niveles de la Realidad aparece en nuestro conocimiento de la naturaleza, de la sociedad y de nosotros mismos, como una estructura compleja: cada nivel de Realidad es lo que es, gracias a todos los niveles existen al mismo tiempo. (NICOLESCU, 2008b, p. 22).

Desde el punto de vista transdisciplinario, la complejidad es la forma moderna del principio, muy antiguo, de la interdependencia universal. $\mathrm{Y}$ el principio de interdependencia universal acarrea un nivel tal de integración los niveles de Realidad y de percepción de Realidad, que implican una extrema simplicidad. Una simplicidad tal que sólo puede ser captada por medio del lenguaje simbólico.

Todos los niveles de la Realidad están interconectados a través de la complejidad. 'El principio de la interdependencia universal' acarrea implícitamente el máximo posible que la mente humana pueda imaginar, la simplicidad de la interacción de todos los niveles de la Realidad. Esta simplicidad no puede ser capturada por el lenguaje matemático, sino sólo por el lenguaje simbólico... Sin embargo, esta unificación no puede ser descrita por una teoría científica. Por definición, la ciencia excluye la noresistencia. La ciencia, como se define hoy en día, está limitada por su

\footnotetext{
${ }^{14}$ Las negrillas son mías.
} 
propia metodología.... La unificación del Sujeto se realiza por la acción del Tercero secretamente incluido, que transforma el conocimiento en comprensión. 'Comprender' significa la fusión del conocimiento y del ser. (NICOLESCU, 2008b, p. 20).

Con este axioma volvemos al comienzo de nuestra reflexión y al meollo mismo del conocimiento transdisciplinar. Recordemos que el conocimiento transdisciplinar se da entre, a través y más allá de las disciplinas. Pero, a estas alturas de la reflexión ¿Qué puede significar este "más allá”?

El más allá, nos relaciona con la finalidad última del conocimiento transdisciplinar: la comprensión del mundo actual, cuyo imperativo fundamental es la unidad del conocimiento. La unidad del conocimiento y la comprensión de sí mismo y del mundo no pasan a través de una teoría, sino una nueva racionalidad, de una nueva visión del mundo que involucra la totalidad de los niveles de Realidad, la totalidad de los niveles de percepción de la Realidad y la totalidad de las relaciones isomórficas entre ambas por medio del ahora tercero secretamente (ontológicamente) incluido, que se nos hace evidente a través del postulado de epistemológico o de la complejidad.

Es cierto que hay una coherencia en el ensamblaje de todos los niveles de la Realidad. Pero esta coherencia está orientada: hay una flecha que asocia la totalidad de la información transmitida de un nivel a otro. En consecuencia, la coherencia, si se limita sólo a los niveles de la Realidad, se detiene o bien en el nivel 'más alto' o en el nivel 'más bajo'. Para que la coherencia continúe más allá de estos dos umbrales, de manera que haya una unidad abierta, hay que considerar que el ensamblaje de todos los niveles de Realidad se prolonguen hacia una zona de no-resistencia a nuestras experiencias, representaciones, descripciones, imágenes 0 formalizaciones matemáticas. El nivel 'más alto' o el nivel 'más bajo' de todos los niveles de Realidad se unen a través de una zona de transparencia absoluta. La zona de no-resistencia corresponde aquí a lo sagrado, es decir, a lo que no sufre ninguna racionalización. La proclamación de la existencia de un solo nivel de Realidad elimina lo sagrado, es el precio que hay que pagar al reducir la Realidad a un solo y único nivel de Realidad...El tercero secretamente (ontológicamente) incluido es el guardián de nuestro misterio irreductible, el único fundamento posible para la tolerancia y la dignidad humana. Sin el tercero secretamente incluido todo es ceniza. (NICOLESCU, 1999, p. 10). 
Lo sagrado, así definido, es decir como la presencia de la irreductiblemente real de la Realidad, es una necesidad epistemológica y ontológica para una aproximación epistemológica al Objeto y al Sujeto transdisciplinar (NICOLESCU, 1998). Lo sagrado no es un una etapa superada de la condición humana, sino la condición estructurante de la misma. Sin la presencia de lo sagrado, todo se desvanece.

Uno puede negar o confirmar la presencia de lo sagrado en el mundo y en sí mismo, pero epistemológicamente siempre tendremos que hacer referencia a lo sagrado, para desarrollar un discurso coherente sobre la Realidad. ... Lo sagrado es aquello que une. Se unió de acuerdo a su significado etimológico con la palabra 'religión' (religare - relier), pero no es, por sí mismo, un atributo de una u otra religión. Lo sagrado es la experiencia fundamental, ella se traduce por el sentimiento que conecta a las personas y cosas y, por lo tanto, genera en las profundidades del ser humano, el respeto absoluto a la alteridad unida por la vida común en una y la misma tierra. La abolición de lo sagrada llevó a la abominación de Auschwitz... Los orígenes del totalitarismo residen en la abolición de lo sagrado. Lo sagrado, como una experiencia de lo real irreductible, es efectivamente el elemento clave en la estructura de la conciencia y no simplemente una etapa en la historia de la conciencia. Cuando este elemento se viola, desfigura o mutila, la historia se convierte en criminal. Esta zona es una zona de no-resistencia cuando el sujeto y el objeto se consideran por separado. Pero paradójicamente, aparece como un espacio de resistencia absoluta cuando el sujeto y el objeto están unificados. Como esta zona se resiste a toda comprensión, sea cual sea su nivel. En ella se da la mutación entre la no-resistencia y resistencia absoluta. Lo sagrado adquiere un estatus de Realidad, como los niveles de la Realidad, Pero, en un nuevo nivel de la Realidad, que escapa a todo conocimiento. Es la comprensión del ser del ente. Sin embargo, lo sagrado no se opone a la razón pues en la medida en que asegura integración entre el sujeto y el objeto, lo sagrado hace parte constitutiva de la nueva racionalidad. Conviene designar esta zona de resistencia absoluta con la palabra 'sagrado' en tanto que esclarece al tercero secretamente (ontológicamente) incluido que concilia la trascendencia inmanente y la inmanencia trascendente. Este reencuentro es la condición insustituible de nuestra libertad y nuestra responsabilidad. En este sentido, lo sagrado aparece como fuente última de nuestros valores (NICOLESCU, 1999, p. 12).

\section{Conclusiones}

Lo sagrado, transdisciplinariamente considerado, es la fuente axiológica de la condición humana, y como tal, genera en el ser humano una visión y una actitud transcultural. Es decir, una actitud de apertura hacia aquello que se da en, a través y más allá de las culturas; que se da en, a través y más allá de las religiones, 
generando lo que aquí vamos a llamar la actitud transcultural, transreligiosa y transhumana:

La transculturación designa la apertura de todas las culturas hacia aquello que pasa a través de ellas y las trasciende. Se refiere a la actualidad transhistórica, noción introducida por Eliade, para referirse a lo impensable, lo impensado y la epifanía. Lo transcultural no significa un tipo único de la cultura, sino la unidad abierta y trascendente de todas las culturas. La actitud transcultural no está en contradicción con ninguna tradición cultural, religiosa o espiritual, o con cualquier corriente agnóstico o atea, en la medida en que estas tradiciones y corrientes se determinan ante la cuestión de lo sagrado. De hecho, la presencia de lo sagrado es nuestra propia transpresencia humana en el mundo... La actitud transcultural no es simplemente un proyecto utópico, sino una necesidad -que está grabada en lo más profundo de nuestro ser-. A través de la transculturación, el conflicto de las culturas -una amenaza cada vez más presente en nuestro tiempo- ya no tiene razón de ser. $\mathrm{Si}$ lo transcultural pudiera encontrar su propio lugar en la modernidad, la noguerra entre civilizaciones podría tener lugar (NICOLESCU, 2004, p.145).

Lo sagrado, transdisciplinariamente considerado, es la fuente axiológica de la condición humana, y como tal, genera en el ser humano una visión y una actitud transreligiosa. Es decir, una actitud de apertura hacia aquello que se da en y a través de las religiones, pero que va más allá de ellas.

Lo sagrado, como una experiencia fundamental, es la fuente de una actitud transreligiosa. La transdisciplinariedad no es ni religiosa ni noreligiosa: es transreligiosa. La actitud transreligiosa, desde una visión transdisciplinaria, es la que nos permite llegar a conocer y apreciar las tradiciones religiosas específicas y las tradiciones no-religiosas que nos son extrañas, percibir mejor las estructuras subyacentes que les son comunes, y así lograr una visión transreligiosa del mundo. La actitud transreligiosa no está en conflicto con ninguna tradición religiosa, ni con ninguna corriente agnóstica o atea, en la medida en que estas tradiciones y corrientes reconocen la presencia de lo sagrado. La presencia de lo sagrado es, de hecho, nuestra trans-presencia dentro del mundo. Si la actitud trans-religiosa es generalizada, se imposibilitarán todas las guerras religiosas. La actitud transreligiosa no es un mero proyecto utópico: se inscribe en lo más profundo de nuestro ser. (NICOLESCU, 1999, p. 12). ${ }^{15}$

La transdisciplinariedad se presenta como un marco metodológico desde el cual poder ir más allá de la confrontación entre la ciencia y la religión,

\footnotetext{
${ }^{15}$ La cursivas son mías.
} 
posibilitando una nueva espiritualidad desde la intercomunicación entre la cultura tecno-científica y la cultura espiritual (NICOLESCU, 2007).

La diferencia crucial entre las disciplinas académicas por un lado, y el de las diferentes culturas y religiones en el otro, se puede entender fácilmente en nuestro enfoque. Las culturas y las religiones no se refieren, como lo hacen las disciplinas académicas a diferentes niveles de la Realidad, sino que se refieren a una Realidad unificada: implican simultáneamente uno o varios niveles de realidad del Objeto, uno o varios niveles de Realidad del Sujeto y de la zona de no-resistencia del tercero secretamente Incluido. La tecnociencia está enteramente situado en la zona del Objeto, mientras que las culturas y las religiones se cruzan todos los tres términos: el Objeto, el Sujeto y el Tercero Incluido. Esta asimetría demuestra la dificultad de su diálogo: este diálogo puede ocurrir sólo cuando hay una conversión de la tecnociencia hacia los valores, es decir, cuando la cultura tecno-científica se convierte en una verdadera cultura. Es precisamente esta conversión que la transdisciplinariedad es capaz de realizar. Este diálogo es metodológicamente posible, debido a que el Tercero Incluido atraviesa todos los niveles de la realidad (NICOLESCU, 2008a, p. 515).

En síntesis, la metodología transdisciplinar permite definir tres tipos de conocimiento o de significado de la Realidad y de nosotros mismos:

1. Un significado horizontal - es decir, el de las interconexiones en un solo nivel de Realidad. Esto es lo que la mayoría de las disciplinas académicas hacen;

2. Un significado vertical- es decir, el de las interconexiones que implican varios niveles de Realidad. Esto es lo que la poesía, el arte o la física cuántica hacen, y;

3. Un significado del significado - es decir, el de las interconexiones que involucran toda la Realidad -el Sujeto, el Objeto y el Tercero Incluido-. Este es el objetivo último de la investigación transdisciplinaria. (NICOLESCU 2008a, p. 512) (Ver gráfica No. 8) 


\section{Gráfica 8: Realidad transdisciplinaria o trans-realidad.}

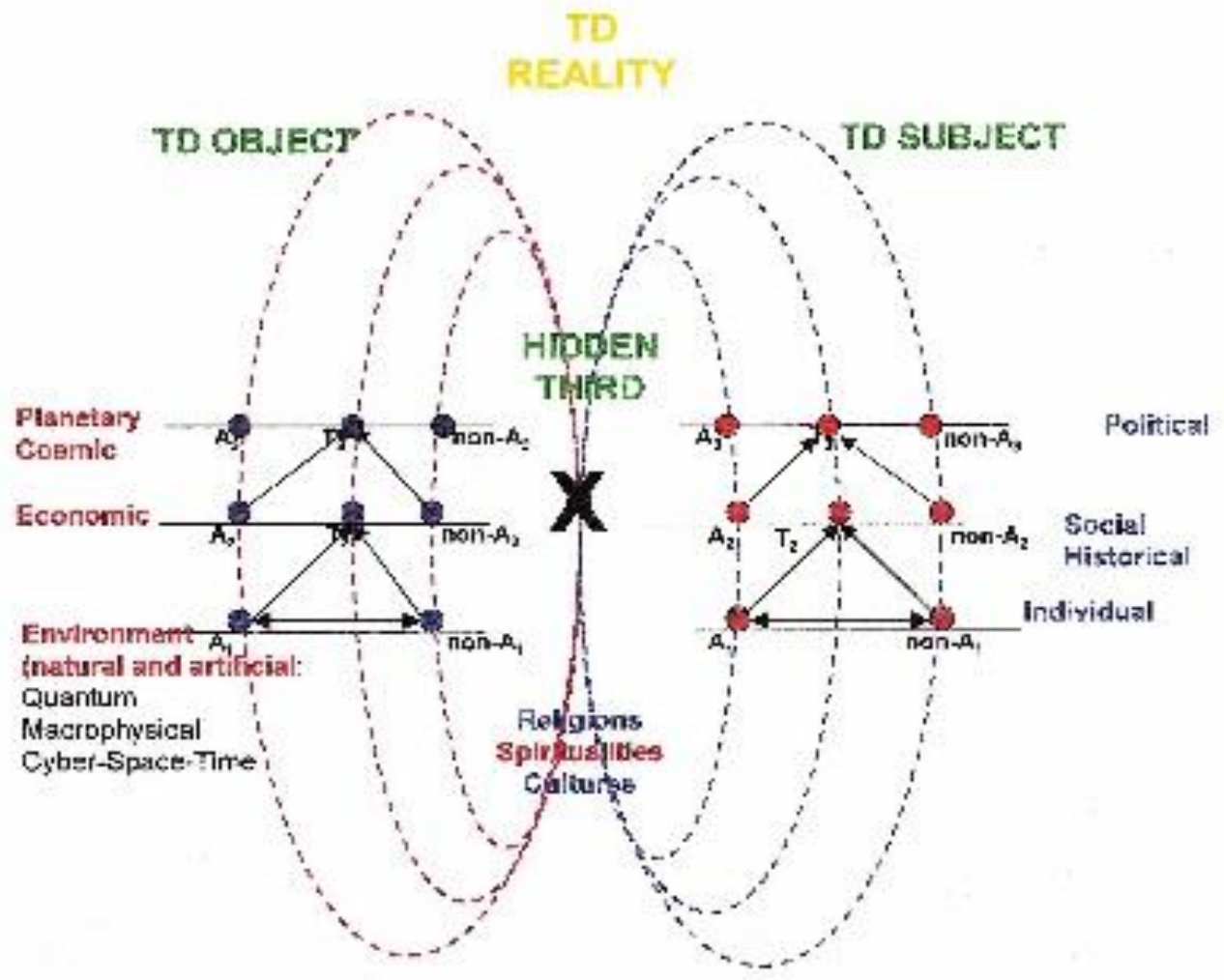

Fuente: NICOLESCU, 2011b -ppt-

La metodología y el conocimiento transdisciplinar exige una nueva forma de humanismo: el transhumanismo que ofrece a cada ser humano la mayor capacidad para el desarrollo científico, religioso y espiritual. Se trata de ofrecer un dispositivo para el conocimiento de lo que está en, a través y más allá de los seres humanos. 


\section{REFERENCIAS}

BECK, U. La sociedad del riesgo. Barcelona: Editorial Paidós, 2006a.

BECK, U. La sociedad del riesgo: hacia una nueva modernidad. Madrid: Ediciones Paidós Ibérica, 2006b.

BECK, U. La sociedad del riesgo global. Madrid: Siglo XXI Editores, 2006c.

BECK, U.; GIDDENS, A.; LASH, S. Modernización reflexiva: política, tradición y estética en el orden social moderno. Madrid: Alianza Editorial, 2008.

BERGER, P. L.; BERGER, Brigitte; KELLNER, Hansfried. Un mundo sin hogar. Modernización y conciencia. Santander: Sal Terrae, 1979.

BERGER, P.; LUCKMANN, T. La construcción social de la realidad. Traducción de Silvia Zuleta. Madrid: Amorrortu Editores, 1986.

BERGER, P.; LUCKMANN, T. The Social Reconstruction of Reality. Londres: The Penguin Press, 1967.

BERGER, P; KELLNER, H. The Homeless Mind: Modernization and consciousness. New York: Randonm House, 1973.

BONETE PERALES, E. Peter L. Berger: Una teoría sociológica de la modernidad. Revista Religión y cultura, Barcelona, no. 175, p. 557-590, 1990.

CAPRA, F. Los dos paradigmas. En: El punto crucial. Ciencia, sociedad y cultura naciente. La necesaria visión de una nueva realidad. Una reconciliación entre ciencia y espíritu humano para hacer posible el futuro. Barcelona: Ediciones Integral, 1985 .

CORBÍ, M. La necesidad ineludible del cultivo de la cualidad humana y de la cualidad humana profunda en nuestras sociedades, como una indagación libre en comunicación y en servicio. Justificación de la temática para el 10 Encuentro Internacional anual de Investigadores de la red de investigación en epistemología axiológica. Documento de trabajo, 2014. Disponible en:

<http://www.cetr.net/es/nuestros_libros/10_la_necesidad_ineludible_del_culti>. Acceso el 12 oct. 2014.

CORBI, M. Necesidad de uma epistemologóa axiológica, En: 8 Encuantro Interncaional CETR. La crisis axiológicoa raíz de todas las crisis que sufre nuestro mundo ¿Cómo maejarnos con ella? Barcelona: CETR-Bubok, 2013, pp. 1542.

CORBÍ, M. La construcción de proyectos axiológicos colectivos. Principios de epistemología axiológica I. Barcelona: Bubok Publishing, 2013c. pp. 310-321. 
CORBÍ, M. La sabiduría de nuestros antepasados para las sociedades en tránsito. Principios de epistemología axiológica II. Barcelona: Bubok Publishing, 2013d. p.227-304.

CORBÍ, M. Religión sin religión o hacia una espiritualidad laica. Christus, Revista de teología, ciencias humanas y pastoral, [s.l.], Ano LXXIV, n. 776, p. 38-46, jan./fev. 2010a.

CORBÍ, M. El cultivo de la cualidad humana y de la cualidad humana profunda, Boletín CETR, agosto-septiembre 2010b, tomado de

http://www.cetr.net/modules.php?name=News\&file=article\&sid=657

CORBÍ, M. A la intemperie. Meditaciones. Barcelona: Verloc-CETR, 2009.

CORBÍ, M. El cultivo de la cualidad humana y de la cualidad humana profunda. In: 5 Encuentro de Can Bordoi: La espiritualidad como cualidad humana y su cultivo en una sociedad laica. Barcelona: Ediciones CETR, 2008a.

CORBÍ, M. Hacia una espiritualidad laica. Sin creencias, sin religiones, sin dioses. Barcelona: Editorial Herder, 2007.

JONAS, H. El principio de responsabilidad. Ensayo de una ética para la civilización tecnológica. Barcelona: Editorial Herder, 1995.

MCGREGOR, Sue L. T . Demystifying transdisciplinary ontology: multiple levels of reality and the hidden third. 2011a. Disponible en:

<http://integralleadershipreview.com/1746-demystifying-transdisciplinary-ontologymultiple-levels-of-reality-and-the-hidden-third/>. Acceso el o6 oct. 2014.

MCGREGOR, Sue L. T. The nature of transdisciplinary research and practice. 2011b. Disponible en: <http://www.kon.org/HSwp/archive/transdiscipl.pdf >. Acceso el 06 oct. 2014.

MORIN. E \& KERN, A, Tierra patria, Barcelona: Editorial Kairós, 1993.

NICOLESCU, B. Transdisciplinary: the hidden third, between the subject and object. Human \& social Studies. Research and practice, v. 1, n. 1, p. 13-28, nov. 2012. Disponiblel en: <http://degruyter.com/view/j/hssr.2012.1.issue-1/v10317-0120005/v10317-012-0002-5.xml?format=INT>. Acceso el 29 sept. 2014.

NICOLESCU, B. The need for transdisciplinarity in higher education. Keynote speaker talk at the International Higher Education Congress "New Trends and Issues". may, $27^{\text {th }}-29^{\text {th }}, 2011$. Istanbul, Turkey. Disponible en:

<http://basarab.nicolescu.perso.sfr.fr/Basarab/Docs_articles/Istanbul_UIK2011.pdf>. Acceso el 29 sept. 2014. 
NICOLESCU, B. The need for transdisciplinarity in higher education. Ppt File Keynote Speaker Talk at the International Higher Education, 2011b. Disponible en: <http://es.scribd.com/doc/23096189o/58283166-Basarab-Nicolescu-the-NEED-forTRANSDISCIPLINARITY-in-HIGHER-EDUCATION-Ppt-File-Keynote-Speaker-Talk-atthe-International-Higher-Education-Co>. Acceso en: 29 sept. 2014.

NICOLESCU, B. Spiritual dimension of democracy. Utopia or necessity? In: MARGA, Andrei; BERCHEIM, Theodor; SADLAK, Jan (Ed.). Living in truth: a conceptual framework for a wisdom society and the European construction. Cluj-Napoca: Cluj University Press, 2008a. p. 509-516

NICOLESCU, B. The Idea of Levels of Reality and its Relevance for non-reduction and personhood. The mini-conference at Opening talk in International Congress "Subject, Self, and Soul: Transdisciplinary Approaches to Personhood". Universidad Pontificia Comillas, Madrid, 2008. In: Transdisciplinarity in Science and Religion. n. 4. Bucarest: Curtea Veche, 2008b. p. 11-26. Disponible en:

<http://basarab.nicolescu.perso.sfr.fr/Basarab/Docs_articles/Metanexus20o8TSR4.htm> . Acceso el 04 oct. 2014.

NICOLESCU, B. La transdisciplinariedad como marco metodológico para ir más allá del debate entre ciencia y religión. 2007. Disponible en:

<http://www.metanexus.net/essay/transdisciplinarity-methodological-framework-goingbeyond-science-religion-debate>. Acceso el o4 oct. 2014.

NICOLESCU, B. Toward a methodological foundation of the dialogue between the technoscientific and spiritual cultures. Opening talk at the 6th International Congress on Philosophy and Culture "Differentiation and Integration of Worldviews: Dynamics of Dialogue Between Cultures in the XXI Century”. Sankt Petersburg, Russia. November 2003, Russian Academy of Science. In: MOREVA, Liubava (Ed.).

Differentiation and Integration of Worldviews. Series "International Readings on Theory, History and Philosophy of Culture”, n. 18. Saint Petersburg: Eidos, 2004. p. 139152.

NICOLESCU, B. Le tiers et le sacré. Bulletin Interactif du Centre International de Recherches et Études transdisciplinaires, n 14, p. 1-14, 1999. Disponível em: <http://ciret-transdisciplinarity.org/bulletin/b14c7.php>. Acesso em: 04 out. 2014.

NICOLESCU, B. Le tiers inclus: de la physique quantique à l'ontologie. Bulletin Interactif du Centre International de Recherches et Études transdisciplinaires, n. 13. Centre International de Recherches et Études Transdisciplinaires, [s.l.], 1998.

NICOLESCU, B. La transdisciplinariedad. Manifiesto. Mónaco: Editions du Rocher, 1996. Disponível em: <http://basarab.nicolescu.perso.sfr.fr/ciret/espagnol/visiones.htm>. Acesso em: 10 out. 2014.

OSORIO, S. La bioética a la luz de las epistemologías de segundo orden II: el aporte crítica de Edgar Morin y Marià Corbí. Bogotá: UMNG-AF\&M Producción Gráfica S.A.S. 2014b. 
OSORIO, S, Camino hacia la epistemología axiológica. El aporte de la teología fundamental, En: M.Corbí (Coord.), Indagaciones sobre la construcción de una epistemología axiológica, Barcelona: CETR-Bobuk, 2014d, pp. 151-200.

OSORIO, S. Ciencias de la complejidad, pensamiento complejo y conocimiento transdisciplinar. In: CORBÍ, Marià. La crisis axiológica raíz de todas las crisis que sufre el mundo actual ¿Cómo manejarnos con ella? Barcelona: CETR-Bubok, 2013e, pp. 223-264.

OSORIO, S. La emergencia de una nueva racionalidad. In: OSORIO, S. Bioética y pensamiento complejo I: un puente en construcción. Bogotá: UMNG-Afán gráfica Ltda, $2013^{2}$. p. 21-42.

OSORIO, S. Cátedra Humanitas: Edgar Morin: pensador planetário. Bogotá: UMNG-ALVI impresores Ltda, 2012a.

OSORIO, S. Camino hacia la transdisciplinariedad. La paradigmatología en Edgar Morin. In: OSORIO, S. Pensar desde la educación superior. Una reflexión transdisciplinar. Bogotá: Alvi Impresores-UMNG, 2010. p. 142-166.

OSORIO, S. De la "teoría crítica de la sociedad” a la "paradigmatología” de Edgar Morin. In: MALDONADO CASTAÑEDA, Carlos Eduardo (Ed.). Complejidad: revolución científica y teoria. Bogotá: Editorial Universidad del Rosario, 2009. p. 145-173.

OSORIO, S. El desafío de la complejidad. In: OSORIO, S. (Coord.). Bioética y pensamiento complejo II: estrategias para enfrentar el desafío planetário. Bogotá: UMNG-Archel publicidad, 2008a. p. 24-44.

OSORIO, S. Aproximaciones a un nuevo paradigma en el pensamiento científico. In: MORENO, J.C. et al. Manual de iniciación pedagógica al pensamiento complejo, UNESCO-ICFES-Corporación Complexus. Quito: Ediciones jurídicas Gustavo Ibáñez, 2003. p. 59-94.

OSORIO, S. ¿Es nuestra identidad nacional tradicional, moderna o posmoderna? Revista Universitas Humanística, Bogotá, Pontificia Universidad Javeriana, Facultad de ciencias sociales. Ano XXIV, v. 41, p.108-116, jan./jun. 1995.

OSORIO GARCÍA, Sergio Néstor. Una nueva dimensión epistemológica para la teología: la Teología de la Liberación y el desafío epistemológico (A new epistemological dimension to theology: liberation theology and epistemological challenge).. Horizonte, Belo Horizonte, v. 11, n. 32, p. 1754-1768, out./dez. 2013. Disponível en:

<http://periodicos.pucminas.br/index.php/horizonte/article/view/6351>. Acceso el: 04 Feb. 2015 .

POTTER, V. Bioethics, bridge to the future. New York: Englewood Cliffs, Prentice Hall, 1971. 
POTTER, V. Global Bioethics: building on the Leopold Legacy. East Lansing: Michigan State University Press, 1988.

SNOW, C. Las dos culturas. En Ensayos científicos. Ciencia y desarrollo. México: FCE, 1980.

WIKIPEDIA. La enciclopedia livre. Ulrich Beck. Disponible en:

<http://es.wikipedia.org/wiki/Ulrich_Beck>. Acceso el 23 julio 2014.

WUTHNOW, R.; HUNTER, J. D.; BERGESEN, A.; KURZWEIL, E. Análisis cultural: la obra de Peter L. Berger, Mary Douglas, Michael Foucault y Jürgen Habermas. Barcelona: Editorial Paidós, 1998. p. 17-19; 31-90; 267-291. 